\title{
JUURNAL.RU
}

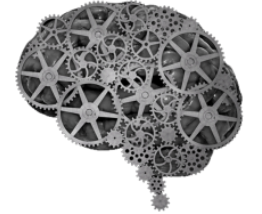

COMPANY GROUP "INTELLEKT"

Башмаков А.С., Дягилева Е.П., Зайкова Е.О., Леонтьева Е.В. Кемеровская государственная медииинская академия Кемерово, Россия

doi: 10.18411/1j2016-5-2-02

\section{Катализ реакции между гидроксиламмонием и нитритом}

Реакция между $\mathrm{NH} 3 \mathrm{OH}+$ и $\mathrm{NO} 2-$ представляет интерес как способ получения чистого N2O. Эта реакция оказалась удобной моделью для исследования катализа реакций в растворах.

Цель работы - разработать способ титриметрического исследования кинетики рассматриваемой реакции, исследовать способы и закономерности ее катализа.

Для определения суммарной концентрации нитрита и гидроксиламмония мы разработали методику обратного титрования броматом калия с йодометрическим окончанием. Адекватность этой методики была доказана титрованием стандартных растворов $\mathrm{NaNO} 2$ и $\mathrm{NH} 3 \mathrm{OHCl}$. Оба эти вещества $\mathrm{KBrO} 3$ в кислой среде окисляет до нитрата.

Начальные концентрации $\mathrm{NaNO} 2$ и $\mathrm{NH} 3 \mathrm{OHCl}$ в реакционной смеси были одинаковы и равны $0,0500 \mathrm{M}$. Реакцию проводили при комнатной температуре $\left(25^{\circ} \mathrm{C}\right)$ в присутствии: 1) $\mathrm{H} 3 \mathrm{BO} 3$ в концентрации $\left.0,5 \mathrm{M}, 2\right)$ NaH2PO4 (1 M) + Na2HPO4 (0,12 M), 3) H3BO3 (0,5 M) + CuSO4 (0,005 M), 4) H3BO3 (0,5 M) + Na2SO4 (0,005 M). Борную кислоту и фосфаты использовали для поддержания постоянного $\mathrm{pH}$ реакционной смеси, который во всех опытах был равен 4,68. Предварительно мы установили, что добавки Н3ВО3, NaH2PO4, $\mathrm{Na} 2 \mathrm{HPO} 4$ в указанных концентрациях не влияют на результаты титрования восстановителей по использованной методике. 
Зависимость суммарной концентрации $\mathrm{NaNO} 2$ и $\mathrm{NH} 3 \mathrm{OHCl}$ от времени реакции не описывается кинетическими уравнениями первого и второго порядка. Причина этого в том, что реакция происходит через образование промежуточного продукта - восстановителя, который титруется броматом, предположительно, азотноватистой кислоты $\mathrm{H} 2 \mathrm{~N} 2 \mathrm{O} 2 . \quad$ При таком предположении экспериментальные кинетические кривые соответствуют последовательности реакций

$$
\mathrm{NaNO} 2+\mathrm{NH} 3 \mathrm{OHCl} \rightarrow \mathrm{H} 2 \mathrm{~N} 2 \mathrm{O} 2+\mathrm{H} 2 \mathrm{O}+\mathrm{NaCl}, \mathrm{H} 2 \mathrm{~N} 2 \mathrm{O} 2 \rightarrow \mathrm{N} 2 \mathrm{O}+\mathrm{H} 2 \mathrm{O} .
$$

Из полученных зависимостей суммарной концентрации восстановителей от времени определены константы реакции второго порядка (k2) между NaNO2 и $\mathrm{NH} 3 \mathrm{OHCl}$ и константы реакции первого порядка $(\mathrm{k} 1)$ разложения $\mathrm{H} 2 \mathrm{~N} 2 \mathrm{O} 2$. Из значения этих констант следует: 1) фосфат (дигидрофосфат)-ион катализирует реакцию второго порядка, 2) Ионы меди катализируют обе стадии реакции.

Мы предполагаем, что влияние ионов меди связано с их участием в процессе образования нитрозил-иона, из которого образуется $\mathrm{H} 2 \mathrm{~N} 2 \mathrm{O} 2$ :

$$
\mathrm{Cu}++\mathrm{HNO} 2+\mathrm{H}+\rightarrow \mathrm{Cu} 2++\mathrm{NO}+\mathrm{H} 2 \mathrm{O}, \mathrm{Cu} 2++\mathrm{NO} \rightarrow \mathrm{Cu}++\mathrm{NO}+.
$$




\section{Литература:}

1. Башмаков А.С., Дягилева Е.П., Кургачев Д.А., Леонтьева Е.В. К вопросу о механизме образования $\mathrm{N} 2 \mathrm{O}$ в катализируемой реакции между гидроксиламмонием и нитритом в воде, этиленгликоле и диоксане. // Вестник Кемеровского государственного университета. 2015. №4 - 3 (64). C. $228-232$.

2. Hughes M. N., Stedman G. Kinetics and mechanism of the reaction between nitrous acid and hydroxylamine. Part I // Journal of the Chemical Society. 1963. P. $2824-2830$.

3. Hussian M. A., Stedman G., Hughes M. N. Kinetics and mechanism of the reaction between nitrous acid and hydroxylamine. Part III. The formation of hyponitrous acid // Journal of the Chemical Society. (B). 1968. P. 597 - 603.

4. Morgan T. D. B., Stedman G., Hughes M. N. Kinetics and mechanism of the reaction between nitrous acid and hydroxylamine. Part II. The alkyl hydroxylamines // Journal of the Chemical Society. (B). 1968. P. 344 - 349. 